\title{
Social Media: An Optimal Virtual Environment for Learning Foreign Languages
}

\author{
http://dx.doi.org/10.3991/ijet.v9i5.3911 \\ Rdouan Faizi, Abdellatif El Afia and Raddouane Chiheb \\ Mohammed V Souissi University, Rabat, Morocco
}

\begin{abstract}
The present paper aims at exploring the potential role that social media technologies play in learning foreign languages. For this purpose, a survey was carried out to examine students' and language learners' perceptions and attitudes about using these platforms. Results of the research study revealed that the great majority of the respondents actually use these web-based applications to enhance their language skills. Most importantly, they noted that social media contribute in improving their listening, reading, speaking and writing skills. Accordingly, we strongly recommend that instructors use these online tools in distant, blended, or face-to-face language learning settings.
\end{abstract}

Index Terms-Foreign language learning, social media, students' perceptions, survey

\section{INTRODUCTION}

In the past few years, the Internet was just a means for distributing static information. Today, it has evolved into a set of social websites where people interact and share huge amounts of decentralized information. Thanks to the rapid development of Information and Communication Technologies, the Web has become an interactive and participatory "read-write" universal channel where users are producers and consumers of content.

This new conception of the Web as a collaborative platform has been backed up by the development of a set of online tools, termed social media. The latter refer to a range of Internet-based applications that are based on the ideological and technological foundations of Web 2.0 technologies that allow the production and exchange of user-generated content [1]. Social media include a wide variety of online tools including social networks, blogs, micro-blogs, wikis as well as media sharing and bookmarking websites.

Given their capacity to enable people to connect, share and collaborate, social media applications have an amazing impact on almost every facet of our personal and professional lives and are used by people from all walks of life. But as students make up nearly a third of world internet, these web-based platforms have influenced the way they learn. Actually, students have recourse to social media in nearly every aspect of their life. They use these online communities to interact with friends, play games and watch television. Most importantly, students make use of these web-based tools for learning purposes.

The objective of this paper is, therefore, to examine the potential role that social media technologies may have on students' learning. However, focus in this work will be on foreign language learning. The rest of this paper is organized as follows. Section Two details the potential ad- vantages that social media present to language learners. Section Three presents the results of a study we undertook to analyse students' use of these platforms to improve their foreign language skills. Finally, Section Four gives a brief conclusion.

\section{Social Media ANd Foreign LANGUAGE LEARNING: POTENTIAL BENEFITS}

With the emergence of the world as a global village in which people are communicating with each other in different parts of the planet, learning foreign languages is of utmost importance. In actual fact, success today depends to a large extent on the ability of an individual to function in this globalized world whose members speak a variety of languages.

Given the importance of foreign languages and taking into consideration the limitations of classical learning contexts, many online virtual communities are gaining ground as potential tools that could improve foreign language learning. In fact, thanks to social media and other web 2.0 technologies, students and language learners have enough opportunities that go beyond the classroom walls to practice their language and communication skills.

An overview of a number of research studies conducted on the use of social media in education has proven that these web-based applications have many advantages [2]. Indeed, it has been found out that social media promote communication and interaction amongst students and allow both instructors and students to communicate with each other within or between classes [3]. These internetbased tools are also an effective way to promote a student's engagement and learning power as they enable shy, intimidated or bored students to share ideas and to express their opinions in a more comfortable way [4], [5]. A further educational advantage of these applications is that they promote collaboration because they provide teachers and students with a unique destination where they can share insights and knowledge.

Taking all these educational benefits into consideration, social media can serve as an ideal environment for learning foreign languages. These social applications actually make language learning an easier process by being fun, interactive and interesting. The online platforms that help people connect with each other could also be used to make language learning faster and more engaging.

Via social media, all language enthusiasts can get in touch with native speakers of a variety of languages. Even though basic vocabulary and grammar rules can be well learnt from a non-native speaker, and no matter what language exercises or activities might be done in class, students may still lack listening and speaking skills. The 


\section{SHORT PAPER}

\section{SOCIAL MEDIA: AN OPTIMAL VIRTUAL ENVIRONMENT FOR LEARNING FOREIGN LANGUAGES}

truth is that class activities and discussion topics are not actual real-life situations. By contrast, social media platforms, characterized by the constant availability of native 'instructors', provide a live experience in which a student or language learner can practice his target language in real time. This is actually where the web supplements real life and offers alternative ways for learning languages. Given this fact, the language learner can, through social media, turn a laborious task like studying into something enjoyable by meeting and interacting with native language speakers from around the world.

With or without their teacher's recommendations, students tend to enter social language learning networks where they can get an answer to most of their questions, without having to go through the anxiety of asking it in front of the class. Social networking websites, such as Facebook and Twitter are spaces where a person can practice his language skills with real native speakers. Besides these free online networks, there are specifically designed web-based language learning communities that offer interactive lessons, exercises and tests as well as text, audio and video chat in many languages. Users can, for instance, write a passage in a foreign language such as French or German and submit it to have a native speaker in the network correct their writing.

Social media authoring tools, namely discussion forums, blogs and wikis, are also taking a more predominant role in language learning as they help students improve reading, writing, and discussion skills through cooperative writing opportunities.

Some believe that communicating via these online applications ruin students' writings and reinforces bad writing habits as sentences may contain embarrassing grammar and spelling errors as well as abbreviations. However, research has demonstrated that social media authoring technologies have positive effects on students' writing skills. In a traditional classroom, students often see themselves as writing only to one person, namely the instructor. But in this new wave of virtual social environments, students always put in much more efforts into their writings because they assume that what they write will be for a wider audience.

Media sharing websites are also a valuable resource for language learners of all levels. YouTube or Dailymotion, for example, is a very convenient way to learn a language, to review those grammar points that a student may forget and to reinforce his overall language skills. In these online channels, one can watch or listen to a variety of spoken languages (formal, informal, colloquial, slang) of all genres (debates, talks, shows, movies, etc.) and learn a lot of vocabulary in context, which will undoubtedly help them improve their language proficiency.

Beyond just getting materials from this set of social media tools, language learners can also broadcast themselves. By producing their own videos, students can apply the target language to real-world situations, and by uploading them on social media, they can get feedback on their speaking skills from others [6].

\section{LANGUGAE LEARNERS AND SSOCILA MEDIA}

Having detailed the advantages of using social media in education and in language learning in particular, it is worthwhile to see how students perceive the use this set of online social tools for language learning purposes. This will, actually, be the aim of the present section.

\section{A. Research Methodology}

To examine students' perceptions and attitudes about using social media for learning foreign languages, a research study was carried out by administering an anonymous online questionnaire consisting of a series of closedended questions, which include a list of predetermined answers from which participants can choose. Such questions are opted for because they are quicker to answer and responses are easier to analyze [7]. By using an online questionnaire the intention was to reach the vast majority of participants and achieve a very high response rate.

The questionnaire consisted of three main parts. The first part collected basic demographic data (namely, age, gender and institution) about students. The second part was concerned with eliciting information about students' online social networking membership and usage. The third part gathered information about the subjects' perceptions and attitudes towards using social media for foreign language learning purposes.

The study's target population were students from different institutions of Mohammed V Souissi University, Morocco. A total of 720 students participated in the survey. 308 are females and 412 are males. Their age varies between 18 and 23 . The students completed the survey between March and July 2013.

\section{B. Data Analysis}

Analysis of the collected data has revealed that apart from 5 respondents, who do not seem to be interested in social networking websites, all the surveyed students reported to be members of at least one social network. Results have actually shown that the great majority of informants have a Facebook account. For more information about students' membership in various social online communities, consult Figure 1.

As is clearly seen, the most popular social networks are Facebook (99\%), Google+ (61\%), and Twitter (47\%). The online networks that are less frequently used by students are LinkedIn (34\%), Viadeo (20\%) and MySpace $(8 \%)$. Apart from the latter social website which seems to be unpopular in Morocco, the low rate associated with both LinkedIn and Viadeo may be due to the fact that these online communities are mainly used for work-related purposes. As such, they may not of great use to them as students.

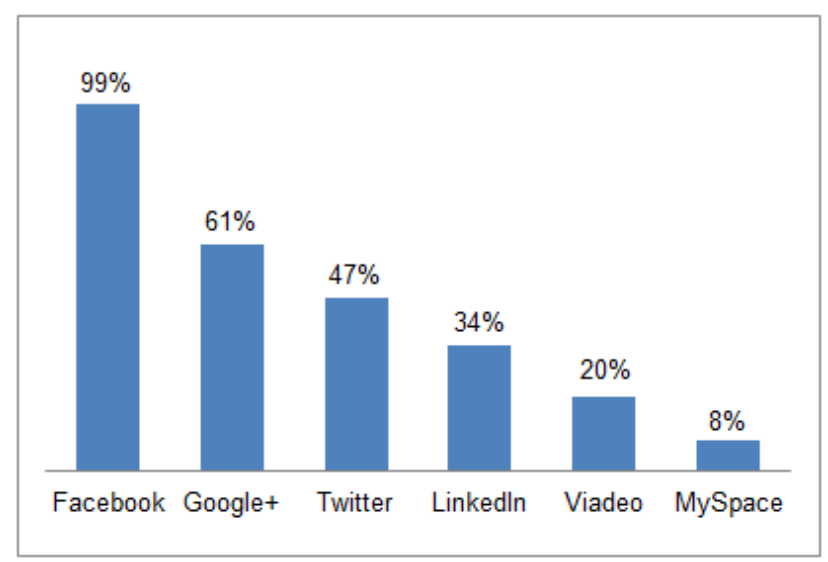

Figure 1. Students' membership in social networking sites 
With regard to the use of social media for learning languages, $81 \%$ of the surveyed students reported that they use this set of online tools to enhance their foreign language skills. The most common languages that the informants are interested in improving or learning are given in Figure 2.

The informants were also asked to choose from a list the social media technologies that they use to boost their language skills. Results showed that most of the students opt for social networks (namely Facebook) and video sharing websites (especially YouTube and Dailymotion). Nonetheless, it has been observed that though there are social online communities, such as Livemocha and Busuu, which are dedicated to language learning, none of the respondents seems to be using them. This implies that students generally prefer to use a platform through which they can not only learn a language but also interact with friends, colleagues and family. The technologies used by students are given in Figure 3.

To investigate the impact that social media may have on boosting the students' language skills, the informants were asked to select the major language skill - listening, speaking, reading, or writing - that they deemed is improving thanks to using social media tools. Figure 4 shows the mean ratings associated with each language skill.

As the figure displays, the main language skill reported to be improving is listening. Of those who participated in the survey, $42 \%$ reported that listening is the most noticeable skill. This may be justified by the fact that given that listening is usually considered as the weakest skill of most language learners, easy access to the rich database of audio and video materials on social media certainly contributes in enhancing this language skill.

Nevertheless, though the surveyed students all agree that social media contribute to enhancing the four language skills with varying degrees, the vast majority of informants (i.e. 91\%) claimed that learning by having recourse solely to online social communities is not sufficient, but should go hand in hand with classroom-based learning.

\section{CONCLUSION}

This paper investigated the promise of using social media for enhancing students' foreign language skills. Results of the research study demonstrated that most of the surveyed students claimed they favor the use of these internet-based applications as these help them improve their four language skills, namely listening, reading, speaking and writing. Given these educational benefits, we can stipulate that social media tools are capable of enriching the language learning experience. Therefore, we recommend that educators use these online social communities whether they work in fully online, blended, or faceto-face language learning environments.

\section{REFERENCES}

[1] Haenlein, M., \& Kaplan, A. (2010). "Users of the world, unite! The challenges and opportunities of social media. Business Horizons", 1(53), 59-68.

[2] Faizi, R, El Afia A \& Chiheb R. (2013). "Exploring the Potential Benefits of Using Social Media in Education". International Journal of Engineering Pedagogy (iJEP). eISSN: 2192-4880

[3] Lin, H. T. \& Yuan, S. M. (2006). "Taking blog as a platform of learning reflective journal". ICWL, 2006, 38-47.

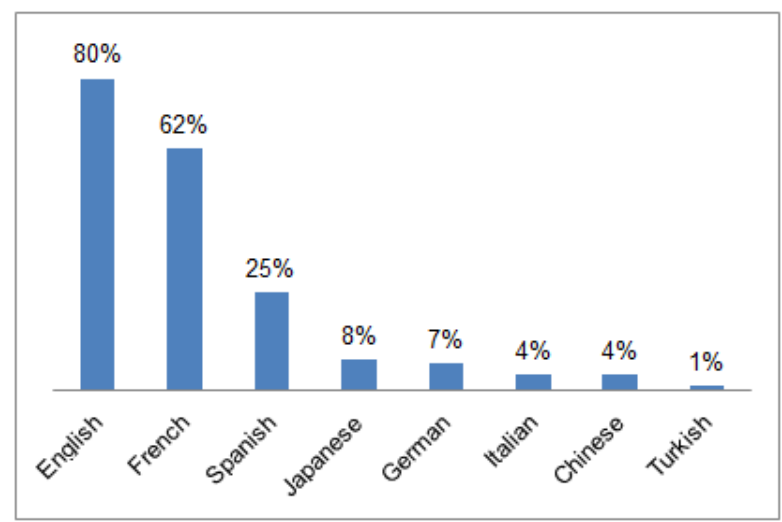

Figure 2. Languages students learn via social media

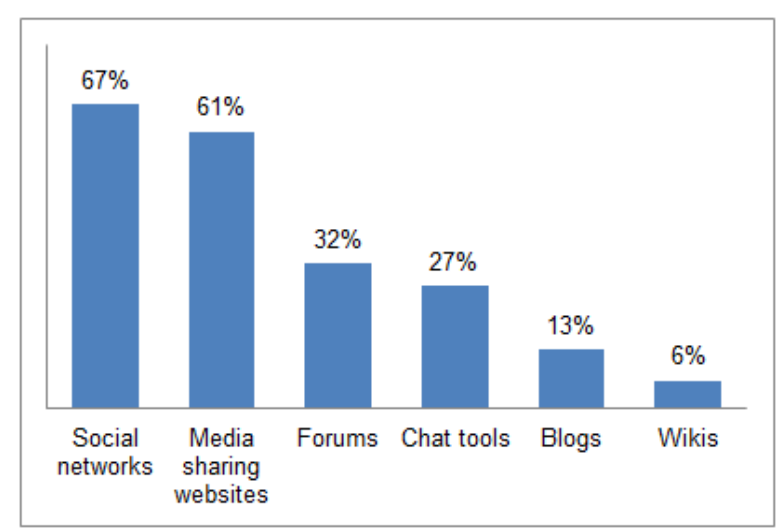

Figure 3. Social media technologies students use

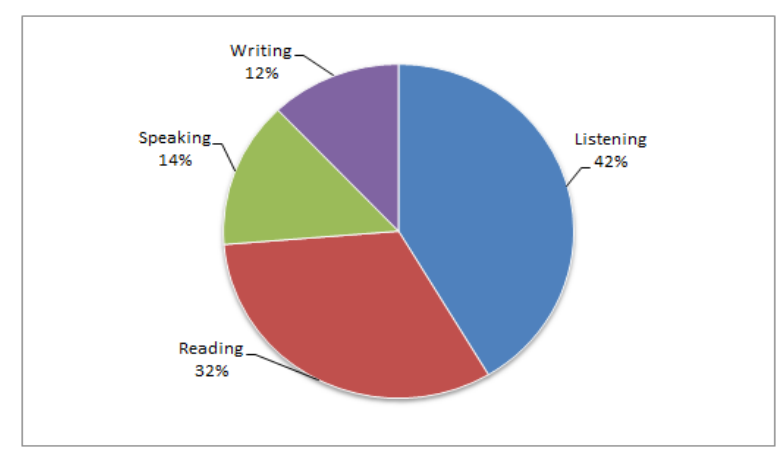

Figure 4. Students' Ratings for the main improved language skill

[4] Rutherford, C. (2010). "Using Online Social Media to Support Preservice Student Engagement". Journal of online learning and teaching, Vol. 6(4).

[5] Rutherford, C. (2012). "Using Social Media to Support Student Engagement". Retrieved from

http://www.drcamillerutherford.com/2012/02 /using-social-mediato-support-student.html

[6] Joseph M. T. (2011). "YouTube for Foreign Languages: You Have to See this Video (Emerging Technologies)". Language Learning \& Technology. Volume 15, Number 1. pp. 10-16. http://dx.doi.org/10.3991/ijep.v3i4.2836

[7] Saunders, M., Lewis, P. \& Thornhill, A. (2009) Research methods for business students, 5 th ed., Harlow, Pearson Education

\section{AUTHORS}

R. Faizi, A. El Afia and R. Chiheb are with ENSIAS, Mohammed V Souissi University, Rabat, Morocco (faizi@ensias.ma, elafia@ensias.ma, chiheb@ensias.ma).

Submitted 24 May 2014. Published as resubmitted by the authors 19 August 2014. 